\title{
On the electronic structure of $\mathrm{Cu}(\mathrm{III})$ and $\mathrm{Ni}(\mathrm{III})$ in $\mathrm{La}_{2} \mathrm{Li}_{1 / 2} \mathrm{Cu}_{1 / 2} \mathrm{O}_{4}, \mathrm{Nd}_{2} \mathrm{Li}_{1 / 2} \mathrm{Ni}_{1 / 2} \mathrm{O}_{4}$, and $\mathrm{Cs}_{2} \mathrm{KCuF}_{6}$
}

\author{
Z. Hu ${ }^{\text {a }}$, G. Kaindl ${ }^{\text {a }}$, S.A. Warda ${ }^{\text {b }}$, D. Reinen ${ }^{\text {b }}$, F.M.F. de Groot ${ }^{\text {c }}$, B.G. Müller ${ }^{\text {d }}$ \\ ${ }^{a}$ Institut für Experimentalphysik, Freie Universität Berlin, Arnimallee 14, D-14195 Berlin-Dahlem, Germany \\ ${ }^{\mathrm{b}}$ Fachbereich Chemie und Zentrum für Materialwissenschaften, Philipps-Universität Marburg, Lahnberge, D-35032 Marburg, Germany \\ ${ }^{\mathrm{c}}$ Solid State Physics, University of Groningen, Nijenborgh 4, 9747 AG Groningen, The Netherlands \\ ${ }^{\mathrm{d}}$ Institut für Anorganische und Analytische Chemie, Justus-Liebig-Universität, Heinrich-Buff-Ring 58, D-35392 Giessen, Germany
}

Received 13 November 1997

\begin{abstract}
The electronic structure of copper and nickel in the oxidation state + III was studied for $\mathrm{La}_{2} \mathrm{Li}_{1 / 2} \mathrm{Cu}_{1 / 2} \mathrm{O}_{4}, \mathrm{Cs}_{2} \mathrm{KCuF}_{6}$, and $\mathrm{Nd}_{2} \mathrm{Li}_{1 / 2} \mathrm{Ni}_{1 / 2} \mathrm{O}_{4}$ by X-ray absorption near-edge structure (XANES) spectroscopy at the $\mathrm{L}_{2,3}$ thresholds of $\mathrm{Cu}$ and $\mathrm{Ni}$ as well as the $\mathrm{K}$-thresholds of $\mathrm{O}$ and $\mathrm{F}$. The observed multiplet structures are well described by cluster configuration-interaction calculations, which result in a high-spin ground state for $\mathrm{Cs}_{2} \mathrm{KCuF}_{6}$ and low-spin ground states for $\mathrm{La}_{2} \mathrm{Li}_{1 / 2} \mathrm{Cu}_{1 / 2} \mathrm{O}_{4}$ and $\mathrm{Nd}_{2} \mathrm{Li}_{1 / 2} \mathrm{Ni}_{1 / 2} \mathrm{O}_{4}$. The simulations yielded $30 \%$ and $40 \% 3 \mathrm{~d}^{8}$ contributions for $\mathrm{La}_{2} \mathrm{Li}_{1 / 2} \mathrm{Cu}_{1 / 2} \mathrm{O}_{4}$ and $\mathrm{Cs}_{2} \mathrm{KCuF}_{6}$, respectively, and $57 \% 3 \mathrm{~d}^{7}$ for $\mathrm{Nd}_{2} \mathrm{Li}_{1 / 2} \mathrm{Ni}_{1 / 2} \mathrm{O}_{4}$ in the ground state. The $\mathrm{O}-\mathrm{K}$ and $\mathrm{F}-\mathrm{K}$ XANES spectra exhibit pronounced preedge peaks that monitor ligand $-2 p$ holes induced by covalency. These preedge peaks move to lower energies with increasing oxidation state of $\mathrm{Cu}$ and $\mathrm{Ni}$ as well as when going from nickelates to cuprates. (C) 1998 Elsevier Science B.V. All rights reserved.
\end{abstract}

PACS: 78.70. Dm; 71.28.+d; 79.60

\section{Introduction}

Oxide ceramics with $\mathrm{Cu}(\mathrm{II}) / \mathrm{Cu}(\mathrm{III})$ and $\mathrm{Ni}(\mathrm{II}) / \mathrm{Ni}$ (III) have gained increased interest since the discovery of high- $T_{\mathrm{c}}$ superconductivity in the cuprates. In $\mathrm{La}_{2-x} \mathrm{Sr}_{x} \mathrm{CuO}_{4}$, an insulator-to-metal transition has been observed upon $\mathrm{Sr}$ doping, including superconductivity. In $\mathrm{La}_{2-x} \mathrm{Sr}_{x} \mathrm{NiO}_{4}$, on the other hand, metallic behavior appears only for very high doping levels [1]. The oxidation states of $\mathrm{Cu}$ and $\mathrm{Ni}$ in $\mathrm{La}_{2-x} \mathrm{Sr}_{x} \mathrm{MO}_{4}(\mathrm{M}=\mathrm{Cu}, \mathrm{Ni})$ are higher than two. From studies of X-ray absorption near-edge structure (XANES) and core-level photoemission (XPS) spectra, it is usually concluded that doping induces holes in the $\mathrm{O}-2 \mathrm{p}$ bands [2-4]. Possible contributions of $3 \mathrm{~d}^{8}$ in case of $\mathrm{Cu}(\mathrm{III})$ and $3 \mathrm{~d}^{7}$ in case of $\mathrm{Ni}$ (III) compounds to the ground-state wave functions were only hesitantly admitted. The reason was lacking experimental evidence in case of $\mathrm{Cu}$ (III) compounds, with the exception of $\mathrm{NaCuO}_{2}$ [5-7] and more recently also of $\mathrm{La}_{2} \mathrm{Li}_{1 / 2} \mathrm{Cu}_{1 / 2} \mathrm{O}_{3.96}$ [8]. So far, the electronic ground state of $\mathrm{Ni}$ (III) in ceramic oxides and fluorides has been studied extensively only by electron-paramagnetic resonance (EPR) and by optical spectroscopy [9].

If one puts too much emphasis on a bond description implying doping-induced holes, one could be misled to interpret the energy splitting of the $\mathrm{Cu}-\mathrm{L}_{3}$ 
XANES spectrum of $\mathrm{La}_{2} \mathrm{Li}_{1 / 2} \mathrm{Cu}_{1 / 2} \mathrm{O}_{3.96}$ as due to transitions from $3 \mathrm{~d}^{9}$ and $3 \mathrm{~d}^{9} \mathrm{~L}$ states ( $\mathrm{L}$ denotes a ligand-2p hole) [8]. The sign of the ligand-to-metal charge-transfer energy, $\Delta$, which determines whether a $3 d^{8}\left(3 d^{7}\right)$ or $3 d^{9} L\left(3 d^{8} L\right)$ contribution dominates in the ground-state wave functions of $\mathrm{Cu}(\mathrm{III})$ [Ni(III)] solids, has been discussed controversially $[6,7,10]$, since several effects in the solid state can lead to a decrease of $\Delta$. (i) An increase in the oxidation state and in the nuclear charge of a $3 \mathrm{~d}^{\mathrm{n}}$ transition-metal cation will lead to a decrease of $\Delta$. Hence, Ni(III) induces a stronger overlap with ligand orbitals than $\mathrm{Ni}(\mathrm{II})$ and $\mathrm{Co}$ (III). Covalency will also increase when turning from a $\mathrm{F}^{-}$ligand atom to a less electronegative one, as e.g. oxygen [7,11]. (ii) Non-local contributions, caused by charge transfer to remote ligands and $3 \mathrm{~d}$ transition-metal ions, may arise when the metal polyhedra are not isolated in the lattice, but interconnected via shared ligand atoms. As a consequence, pronounced shifts of the charge-transfer bands to lower energies may occur, enhancing the apparent covalency effect $[11,12]$.

In order to reach an improved understanding of the electronic structure of $\mathrm{Cu}(\mathrm{III})$ and $\mathrm{Ni}(\mathrm{III})$ compounds, we have studied $\mathrm{La}_{2} \mathrm{Li}_{1 / 2} \mathrm{Cu}_{1 / 2} \mathrm{O}_{4}$, $\mathrm{Nd}_{2} \mathrm{Li}_{1 / 2} \mathrm{Ni}_{1 / 2} \mathrm{O}_{4}$, and $\mathrm{Cs}_{2} \mathrm{KCuF}_{6}$ by XANES spectroscopy in the region of the $\mathrm{L}_{2,3}$ thresholds of $\mathrm{Cu}$ and $\mathrm{Ni}$ as well as the $\mathrm{K}$ thresholds of $\mathrm{O}$ and $\mathrm{F}$. In these systems, the $\mathrm{MO}_{6}$ polyhedra are isolated, which means that non-local effects are not expected to contribute; therefore cluster configuration-interaction calculations are very suitable for a description of these systems. In addition, the studied compounds are stable in air, as distinguished from $\mathrm{NaCuO}_{2}$ and $\mathrm{Li}_{x} \mathrm{Ni}_{1-x} \mathrm{O}$, which had been investigated before $[5,13]$.

\section{Experimental}

The solids $\mathrm{Nd}_{2}\left(\mathrm{La}_{2}\right) \mathrm{Li}_{1 / 2} \mathrm{R}_{1 / 2} \mathrm{O}_{4}(\mathrm{R}=\mathrm{Ni}, \mathrm{Cu})$ and $\mathrm{Cs}_{2} \mathrm{KCuF}_{6}$ were prepared according to experimental procedures described in Refs. [14] and [15], respectively. No impurity phases could be found by $\mathrm{X}$-ray diffraction, and the nickel and copper oxidation states, determined by iodometric titration, were in agreement with stoichiometry. The XANES measurements were performed at the SX700/II mono- chromator operated by the Freie Universität Berlin at the Berliner Elektronenspeicherring für Synchrotronstrahlung (BESSY). For the $\mathrm{O}-\mathrm{K}$ and $\mathrm{F}-\mathrm{K}$ measurements, the fluorescence-yield mode was used (counting measurement), while $\mathrm{Ni}-\mathrm{L}_{2,3}$ and $\mathrm{Cu}-\mathrm{L}_{2,3}$ spectra were taken in the total-electron-yield mode (current measurement). Experimental resolution was 0.4 and $0.7 \mathrm{eV}$ at the $\mathrm{O}-\mathrm{K}$ and $\mathrm{Cu}-\mathrm{L}_{3}$ threshold, respectively, and typical measuring time per point was $1 \mathrm{~s}$. By taking spectra of the compound under study and of a reference compound $(\mathrm{CuO}, \mathrm{NiO})$, the reproducibility of the relative energy scale was found to be better than $10^{-3}$.

The samples were transferred from a clean Ar atmosphere to the experimental UHV chamber, with a base pressure of $10^{-10}$ mbar. The surfaces were cleaned in UHV by scraping with a diamond file. Since the investigated oxides and fluorides are insulators, the samples were charging up during the measurements; however, this does not influence the XANES spectra in a direct way. Furthermore, the $\mathrm{Cu}(\mathrm{III})$ and $\mathrm{Ni}$ (III) compounds were found to be not fully stable in vacuum, particularly when exposed to $\mathrm{X}$-rays. The reason is that a decomposition of the sample surface may occur in UHV resulting in the formation of oxygen-deficient phases at the surface. This surface decomposition grows with increasing temperature and time. Spectral features induced by impurity phases in the samples or by surface oxygen deficiency were extremely weak $(\leqslant 5 \mathrm{~mol} \%)$. They could be identified easily on the basis of their energies, since the energy separation of a spectral component in the $\mathrm{Cu}-\mathrm{L}_{2,3}$ XANES spectrum of a $\mathrm{Cu}(\mathrm{III})$ compound, e.g. from the single peak in the spectrum of $\mathrm{CuO}$ is approximately constant, independent of the specific $\mathrm{Cu}(\mathrm{III})$ compound [5,7]. To limit the effects of impurities, the data-taking periods were restricted to $10 \mathrm{~min}$ after each cleaning procedure.

\section{Results and discussion}

\section{1. $\mathrm{Cu}(I I) / C u(I I I)$}

The solids $\mathrm{La}_{2} \mathrm{Li}_{1 / 2} \mathrm{Cu}_{1 / 2} \mathrm{O}_{4}$ and $\mathrm{Cs}_{2} \mathrm{KCuF}_{6}$ crystallize in the $\mathrm{K}_{2} \mathrm{NiF}_{4}$ and perovskite structure, respectively, with ordered distributions of $\mathrm{Li} / \mathrm{Cu}$ and $\mathrm{K} / \mathrm{Cu}$ over the octahedral sites $[14,15]$. There- 
fore, both systems lack any oxygen-bridged copper neighbors. Copper is in the oxidation state + III in these compounds - a notation widely used by chemists - which does not necessarily imply ' $\mathrm{Cu}^{3+}$, centers, but includes also much smaller effective ionic charges that are reduced by covalency. Optical spectroscopy, structural analysis, and magnetic studies have clearly proved that the $\mathrm{CuF}_{6}$ octahedra in $\mathrm{Cs}_{2} \mathrm{KCuF}_{6}$ are regular and the ground state of $\mathrm{Cu}(\mathrm{III})$ is high-spin $(S=1)$, i.e. $\mathrm{e}_{\mathrm{g}}{ }^{4} \mathrm{e}_{\mathrm{g}}^{* 2}$ in a molecularorbital (MO) description (here, the bonding and antibonding $\left({ }^{*}\right)$ electrons in $3 \mathrm{~d}$ MOs beyond the closed $\mathrm{d}^{6}$ subshell are listed) [16]. The $\mathrm{e}_{\mathrm{g}}\left(\mathrm{e}_{\mathrm{g}}^{*}\right)$ molecular orbitals involve the $\mathrm{d}_{z^{2}}$ and $\mathrm{d}_{x^{2}-y^{2}}$ atomic orbitals of $\mathrm{Cu}$. In contrast, the $\mathrm{Cu}(\mathrm{III}) \mathrm{O}_{6}$ octahedra in $\mathrm{La}_{2} \mathrm{Li}_{1 / 2} \mathrm{Cu}_{1 / 2} \mathrm{O}_{4}$ are strongly tetragonally elongated (almost square-planar), in agreement with a low-spin ground state [14]. Here, the electronic configuration beyond the closed $d^{6}$ subshell $\left(D_{4 h}\right.$ notation) is $b_{1 g}^{2} a_{1 g}^{2} a_{1 g}^{* 2} b_{1 g}^{*}$, with $a_{1 g}\left(a_{1 g}^{*}\right)$ and $b_{1 g}\left(b_{1 g}^{*}\right)$ involving the $\mathrm{d}_{z^{2}}$ and $\mathrm{d}_{x^{2}-y^{2}}$ orbitals, respectively, with their energy degeneracies being lifted in the tetragonal ligand field (Fig. 1a). Copper(II), e.g. in the $\mathrm{K}_{2} \mathrm{NiF}_{4}$-type mixed crystals $\mathrm{La}_{1+x} \mathrm{Sr}_{x}$ $\mathrm{Ga}_{1-x} \mathrm{Cu}_{x} \mathrm{O}_{4}$ [17], is found in tetragonally elongated octahedra as well (due to vibronic Jahn-Teller coupling), with a ground-state electronic configuration as in low-spin $\mathrm{Cu}(\mathrm{III})$, but with an additional electron in the $b_{1 \mathrm{~g}}^{*}$ MO. The wave functions for $b_{1 \mathrm{~g}}$ and $\mathrm{b}_{1 \mathrm{~g}}^{*}$ can be written as:

$$
\begin{aligned}
& \Phi\left(\mathrm{b}_{1 \mathrm{~g}}^{*}\right)=\alpha^{\prime} \mathrm{d}_{x^{2}-y^{2}} \beta^{\prime} \mathrm{L}_{x^{2}-y^{2}} \quad\left(\alpha^{\prime 2}+\beta^{\prime 2} \pm 2 \alpha^{\prime} \beta^{\prime} S \cong 1\right) \\
& \Phi\left(\mathrm{b}_{1 \mathrm{~g}}\right)=\beta^{\prime} \mathrm{d}_{x^{2}-y^{2}}+\alpha^{\prime} \mathrm{L}_{x^{2}-y^{2}}
\end{aligned}
$$

Here, $\mathrm{L}_{x^{2}-y^{2}}$ represents a linear combination of oxygen-2p orbitals (LCAO), symmetry-adapted to $\mathrm{d}_{x^{2}-y^{2}}, S$ is the overlap integral, and $\alpha^{\prime}, \beta^{\prime}$ are MO mixing coefficients. $\Phi\left(\mathrm{b}_{1 \mathrm{~g}}^{*}\right)$ is the ground state of $\mathrm{Cu}(\mathrm{II})$ in a hole description $\left(=\mathrm{b}_{1 \mathrm{~g}}^{* 1}\right)$, with $\mathrm{d}_{x^{2}-y^{2}}$ and $\mathrm{L}_{x^{2}-y^{2}}$ corresponding to $3 \mathrm{~d}^{1}$ and $\mathrm{L}^{1}$, respectively, again in hole description. From the hyperfine structure of copper, observed in an EPR experiment, $\alpha^{\prime}$ was estimated for oxidic $\mathrm{Cu}(\mathrm{II})$ solids as $\alpha^{\prime}=$ $0.87(2)$, i.e. somewhat smaller than for $\mathrm{Cu}(\mathrm{II})$ solids with $\mathrm{F}^{-}$as the ligand $\left(\alpha^{\prime}=0.92\right)$ [17].

The core-level spectra of these strongly correlated systems can be described properly only in a many- (a)
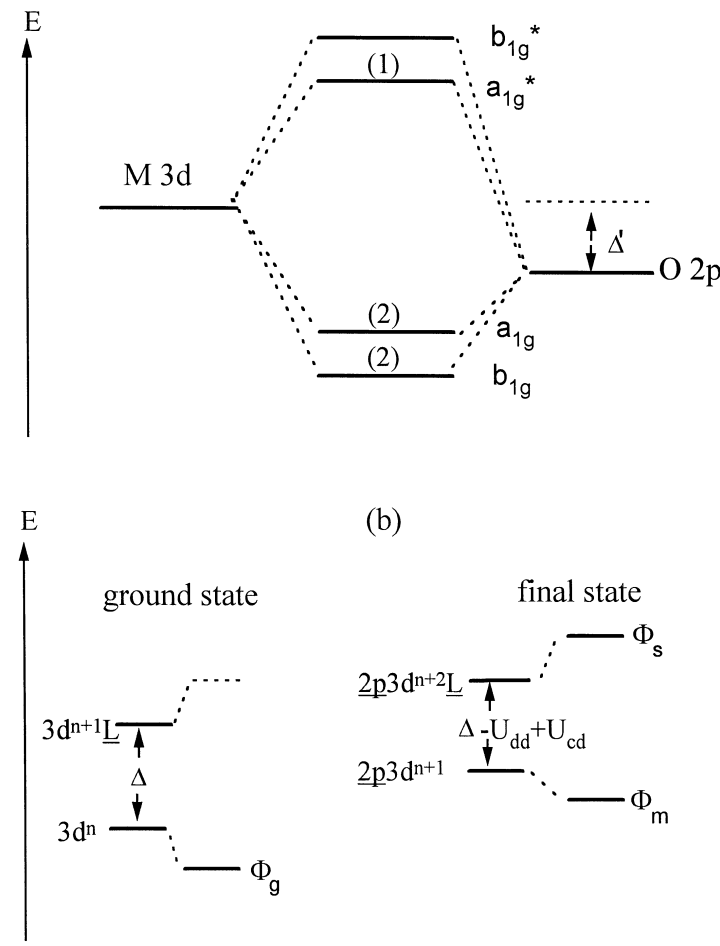

Fig. 1. (a) Qualitative MO energy diagram for $3 \mathrm{~d}^{n}$ cations $(n \geqslant 6)$ in a tetragonal ligand field ( $D_{4 h}$ point group). Only MOs resulting from $d_{x^{2}-y^{2}}\left(b_{1 g}, b_{1 g}^{*}\right)$ and $d_{z^{2}}\left(a_{1 g}, a_{1 g}^{*}\right)$ are displayed, with the electron occupation numbers (in parenthesis) corresponding to low-spin Ni(III). (b) Schematic energy diagram of the many-electron states, originating from $3 \mathrm{~d}^{n}$ cations and the $2 \mathrm{p}$ orbitals of oxygen and fluorine: (left) ground state $\Phi_{\mathrm{g}}\left(3 \mathrm{~d}^{n}, 3 \mathrm{~d}^{n+1} \mathrm{~L}\right.$ intermixed); (right) final states $\Phi_{\mathrm{m}}, \Phi_{\mathrm{s}}$ in $\mathrm{Cu}(\mathrm{Ni})-\mathrm{L}_{2,3}$ X $A N E S$ spectra $\left(2 \underline{\mathrm{p}} 3 \mathrm{~d}^{n+1}, \underline{2 \mathrm{p}} 3 \mathrm{~d}^{n+2} \underline{\mathrm{L}}\right.$ intermixed).

body scheme. In order to reach a physical understanding of the $\mathrm{L}_{2,3}$ XANES spectra, a simple approximation of the Anderson impurity model will be used in this section (see Fig. 1b) $[18,19]$. We define the Hamiltonian of a $3 \mathrm{~d}^{\mathrm{n}}$ system and the corresponding ground-state wavefunction in Eqs. (2) and (3), where for simplicity mixing with $\mathrm{d}^{n+2} \underline{\mathrm{L}}^{2}$ configurations has been neglected:

$$
\begin{aligned}
& H=\left|\begin{array}{ll}
0 & T \\
T & U
\end{array}\right| \\
& \Phi_{\mathrm{g}}=\alpha_{0}\left|3 \mathrm{~d}^{n}\right\rangle+\beta_{0}\left|3 d^{n+1} \underline{L}\right\rangle \quad\left(\alpha_{0}^{2}+\beta_{0}^{2}\right)=1
\end{aligned}
$$

$U=\Delta$ denotes the charge-transfer energy for a 
many-electron system (Fig. 1b); it is different from $\Delta^{\prime}$ in a one-electron description (Fig. 1a) defined as the energy difference between the $3 \mathrm{~d}$ level and the oxygen orbitals; $T$ is the $3 \mathrm{~d} \rightarrow \mathrm{L}$ transfer integral. The configuration mixing coefficients $\alpha_{0}$ and $\beta_{0}$ in the ground state are related to each other in the following way:

$$
\frac{\beta_{0}}{\alpha_{0}}=\frac{\left(\Delta^{2}+4 T^{2}\right)^{1 / 2}-\Delta}{2 T}
$$

It should be emphasized here that the MO mixing coefficients $\alpha^{\prime}, \beta^{\prime}$ are correlated with $\alpha_{0}$ and $\beta_{0}$, but not in an identical way for $\mathrm{d}^{n}$ configurations with $n>1$ (see below). For $\mathrm{CuO}, \Delta=\Delta^{\prime}$ amounts to 1-2 $\mathrm{eV}$, but it is much larger for $\mathrm{CuF}_{2}$. From Eq. (4), we derive $\beta_{0}<\alpha_{0}$, in accordance with the EPR results mentioned above [17], which suggested a ground state with about $85 \%$ and $75 \%$ d character for fluorides and oxides, respectively.

When going from $\mathrm{Cu}(\mathrm{II})$ to $\mathrm{Cu}(\mathrm{III})$ oxides, $\Delta$ decreases significantly, becoming even negative as estimated for $\mathrm{NaCuO}_{2}(\Delta=-2.5 \mathrm{eV})$ [7]. From Eq. (4), a $\beta_{0} / \alpha_{0}$ ratio larger than unity is obtained, implying $3 \mathrm{~d}^{9} \mathrm{~L}$ as the predominant contribution to the ground state. The ground-state electronic configuration in the MO model is $\mathrm{b}_{\mathrm{g}}^{* 2}$ (hole description), which would correspond to $\overline{3} \mathrm{~d}^{9} \mathrm{~L}$ in case of mixing coefficients $\alpha^{\prime}=\beta^{\prime}$ and $\Delta^{\prime}=0$, as can be verified easily from Eq. (1) for the antibonding state. Note that an interpretation of $3 \mathrm{~d}^{9} \mathrm{~L}$ in the sense of ${ }^{\prime} \mathrm{Cu}^{2+}$ $\mathrm{O}^{-}$, is misleading, since the two electronic holes $\left(\mathrm{d}^{1} \mathrm{~L}^{1}\right)$ occupy the same $\mathrm{b}_{1 \mathrm{~g}}^{*}$ MO. Both are equally involved in bonding, and both are completely delocalised between copper and oxygen for $\alpha^{\prime}=\beta^{\prime}$. The real situation with an admixture of $3 \mathrm{~d}^{8}$ leads to $\alpha^{\prime} \geqslant \beta^{\prime}$ and $\Delta^{\prime} \geqslant 0$, implying a strongly covalent $\mathrm{Cu}(\mathrm{III})-\mathrm{O}$ bond with less than $50 \%$ oxygen character, which is in perfect agreement with chemical experience. For the $\mathrm{Cu}(\mathrm{III})-$ fluoride bond, one can expect an increase of the $3 \mathrm{~d}^{8}$ contribution to the ground state. Evidence for this comes from the nephelauxetic effect and from optical electronegativities, defined by C.K. Jørgensen on the basis of the energies of the charge-transfer bands, which indicate that the oxidation state of copper in $\mathrm{Cs}_{2} \mathrm{KCuF}_{6}$ is indeed + III [16].
Fig. 2 shows the $\mathrm{Cu}-\mathrm{L}_{2,3}$ XANES spectra of $\mathrm{La}_{2} \mathrm{Li}_{1 / 2} \mathrm{Cu}_{1 / 2} \mathrm{O}_{4}$ and $\mathrm{Cs}_{2} \mathrm{KCuF}_{6}$ together with the one of $\mathrm{CuO}$ for comparison. The spin-orbit interaction of the $2 \mathrm{p}$ core holes splits the spectra into two parts, those at lower energies originating from $2 \mathrm{p}_{3 / 2}\left(\mathrm{~L}_{3}\right)$ core holes and those at higher energies from $2 \mathrm{p}_{1 / 2}\left(\mathrm{~L}_{2}\right)$ core holes. The single strong peaks $\mathrm{A}^{\prime}$ observed in the $\mathrm{L}_{2}$ and $\mathrm{L}_{3}$ XANES spectra of $\mathrm{CuO}$ are assigned to $2 \mathrm{p} 3 \mathrm{~d}^{10}$ final states arising from a $3 d^{9}$ ground state $(2 \mathrm{p}$ denotes a hole in the $\mathrm{Cu}-2 \mathrm{p}$ core shell). The intrinsic $\mathrm{Cu}-\mathrm{L}_{2,3}$ XANES spectrum of $\mathrm{La}_{2} \mathrm{Li}_{1 / 2} \mathrm{Cu}_{1 / 2} \mathrm{O}_{4}$ contains the strong peaks $\mathrm{B}$ at $1.7 \mathrm{eV}$ above peaks $\mathrm{A}^{\prime}$ and further satellites $\mathrm{C}$, at about $8.4 \mathrm{eV}$ above B. Except for a larger spectral weight of the satellite, the observed spectral features are similar to those previously found for $\mathrm{NaCuO}_{2}$ [5], where the main peak and satellite were basically assigned to $2 \mathrm{p} 3 \mathrm{~d}^{10} \mathrm{~L}$ and $2 \mathrm{p} 3 \mathrm{~d}^{9}$ final states, respectively. The weak shoulders $\mathrm{A}$, observed for all $\mathrm{Cu}(\mathrm{III})$ compounds studied so far at energies close to the

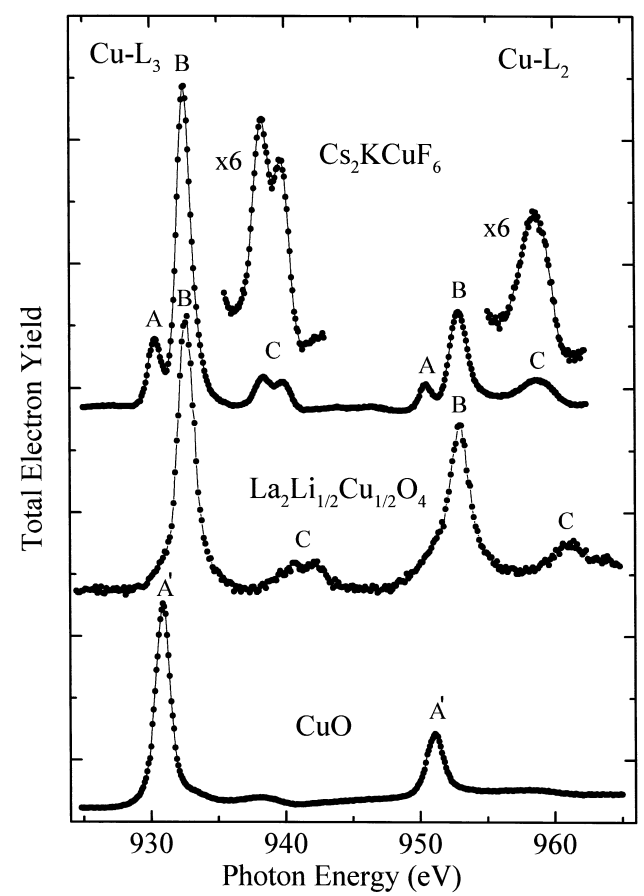

Fig. 2. $\mathrm{Cu}-\mathrm{L}_{2,3}$ XANES spectra of $\mathrm{La}_{2} \mathrm{Li}_{1 / 2} \mathrm{Cu}_{1 / 2} \mathrm{O}_{4}$, $\mathrm{Cs}_{2} \mathrm{KCuF}_{6}$, and $\mathrm{CuO}$ for comparison. The diameters of the filled circles represent upper limits to the statistical errors of the data points. The solid curves through the data points serve as a guide to the eyes. 
peaks $\mathrm{A}^{\prime}$ in the spectrum of $\mathrm{CuO}$, were assigned to $\mathrm{Cu}(\mathrm{II})$ impurities, i.e. impurity phases with a $3 \mathrm{~d}^{9}$ ground state. The spectral weights of the impurity peaks A were found to depend on the purity of the starting material increasing with time after each scraping. In case of $\mathrm{La}_{2} \mathrm{Li}_{1 / 2} \mathrm{Cu}_{1 / 2} \mathrm{O}_{4}$, shoulder $\mathrm{A}$ is barely detectable, definitely ruling out a $3 \mathrm{~d}^{9}$ configuration in $\mathrm{Cu}$ (III) compounds. The absolute energy scale was adjusted to the $\mathrm{Cu}-\mathrm{L}_{3}$ peak $\mathrm{A}^{\prime}$ of $\mathrm{CuO}$ at $931.0 \mathrm{eV}$. Turning from $\mathrm{La}_{2} \mathrm{Li}_{1 / 2} \mathrm{Cu}_{1 / 2} \mathrm{O}_{4}$ to $\mathrm{Cs}_{2} \mathrm{KCuF}_{6}$, satellite $\mathrm{C}$ gets more intense, clearly exhibiting a double-peaked multiplet structure, which is very similar to the $2 \mathrm{p} 3 \mathrm{~d}^{9}$ multiplet of $\mathrm{Ni}$ (II) [20]. This reflects a lower covalency than that of the $\mathrm{Cu}(\mathrm{III}) \mathrm{O}_{6}$ polyhedron (see below), which can be expected from the higher electronegativity of the fluorine ligand. Satellite $\mathrm{C}$ is also observed at the $\mathrm{Cu}-\mathrm{L}_{2}$ threshold, but less well resolved. The weak structure at $938 \mathrm{eV}$ in the spectrum of $\mathrm{CuO}$ is assigned to a $2 \mathrm{p} 3 \mathrm{~d}^{9} 4 \mathrm{~s}$ state, i.e. a transition to the unoccupied conduction band of $\mathrm{CuO}$.

The schematic energy diagram in Fig. $1 \mathrm{~b}$ describes the energies of the ground states (see Eqs. (2) and (3)) and of the $\mathrm{L}_{2,3}$ XANES final states, when configurational mixing occurs according to Eqs. (5) (9):

$$
\begin{aligned}
& H=\left|\begin{array}{cc}
O & T_{\mathrm{f}} \\
T_{\mathrm{f}} & U_{\mathrm{f}}
\end{array}\right| \\
& \Phi_{\mathrm{m}}=\alpha\left|\underline{2 \mathrm{p}} 3 \mathrm{~d}^{8}\right\rangle+\beta\left|\underline{2 \mathrm{p}} 3 \mathrm{~d}^{9} \underline{\mathrm{L}}\right\rangle \\
& \Phi_{\mathrm{s}}=\beta\left|\underline{2 \mathrm{p}} 3 \mathrm{~d}^{8}\right\rangle-\alpha\left|\underline{2 \mathrm{p}} 3 \mathrm{~d}^{9} \underline{\mathrm{L}}\right\rangle \\
& E_{\mathrm{m} / \mathrm{s}}=\frac{1}{2}\left\{\left(U_{\mathrm{f}}^{2}+4 T_{\mathrm{f}}^{2}\right)^{1 / 2} \mp U_{\mathrm{f}}\right\} \\
& \frac{\beta}{\alpha}=\left\{\left(U_{\mathrm{f}}^{2}+4 T_{\mathrm{f}}^{2}\right)^{1 / 2}-U_{\mathrm{f}}\right\} / 2 T_{\mathrm{f}}
\end{aligned}
$$

Here, $T_{\mathrm{f}}$ is the $\mathrm{d} \rightarrow \mathrm{L}$ transfer integral in the final states, and $U_{\mathrm{f}}$ is equal to $\Delta-\mathrm{U}_{\mathrm{cd}}+\mathrm{U}_{\mathrm{dd}}$, where $\mathrm{U}_{\mathrm{cd}}$ and $\mathrm{U}_{\mathrm{dd}}$ denote the $\mathrm{Cu}-2 \mathrm{p}$ core-hole $/ 3 \mathrm{~d}$ and $3 \mathrm{~d} / 3 \mathrm{~d}$ Coulomb interaction, respectively. $\Phi_{\mathrm{m}}$ and $\Phi_{\mathrm{s}}$, as well as the corresponding energy $E_{\mathrm{m} / \mathrm{s}}$, refer to the main peak and the satellite, respectively. The intensity distribution between the main peak $\mathrm{B}$ and satellite $\mathrm{C}$ is determined by the degree of covalent mixing in the ground state and the interference effect in the final states, as described by Eq. (10):

$$
\frac{I_{\mathrm{S}}}{I_{\mathrm{M}}} \cong \frac{\left(\alpha_{0} \beta-\beta_{0} \alpha\right)^{2}}{\left(\alpha_{0} \alpha+\beta_{0} \beta\right)^{2}}
$$

From Eq. (10) one deduces a weak intensity of satellite C. But this weak intensity does not necessarily mean that the $3 \mathrm{~d}^{8}$ contribution to the ground state (or a $2 \mathrm{p} 3 \mathrm{~d}^{9}$ contribution to the final state) is very small. For $T_{\mathrm{f}}=T$ and $\mathrm{U}_{\mathrm{cd}}=\mathrm{U}_{\mathrm{dd}}$, the intensity of the satellite is expected to be almost totally transferred to the main peak. This effect is well known from $\mathrm{M}_{4,5}$ XANES spectra of tetravalent rare-earth compounds [18,21]. However, since we know from energy estimates that $-\mathrm{U}_{\mathrm{cd}}+\mathrm{U}_{\mathrm{dd}} \cong-2 \mathrm{eV}[5,7], \mathrm{U}_{\mathrm{f}}$ is more negative than $\Delta$, which means that for $\mathrm{La}_{2} \mathrm{Li}_{1 / 2} \mathrm{Cu}_{1 / 2} \mathrm{O}_{4}$ one expects that the $2 \mathrm{p} 3 \mathrm{~d}^{10} \mathrm{~L}$ contribution to the final state in the $\mathrm{L}_{2,3}$ XANES spectrum (main peak) is larger than that of $3 \mathrm{~d}^{9} \mathrm{~L}$ in the ground state. Thus the main peaks $\mathrm{B}$ and the satellites $\mathrm{C}$ in the $\mathrm{L}_{2,3}$ XANES spectra of $\mathrm{Cu}$ (III) oxides should be basically assigned to $2 \mathrm{p} 3 \mathrm{~d}^{10} \mathrm{~L}$ and $2 \mathrm{p} 3 \mathrm{~d}^{9}$ final states, respectively, in agreement with previous suggestions [5]. This enhancement of the ligand-hole fraction in the final state is particularly pronounced in case of non-local compounds, where the electron can originate at least partly from remote metal and ligand ions [11,22].

Additional information comes from two further observations. In the sequence $\mathrm{Cs}_{2} \mathrm{KCuF}_{6} \rightarrow$ $\mathrm{La}_{2} \mathrm{Li}_{1 / 2} \mathrm{Cu}_{1 / 2} \mathrm{O}_{4} \rightarrow \mathrm{NaCuO}_{2}$, the energy separation between the main peak and the satellite increases from $6.5 \rightarrow 8.4 \rightarrow 9.0 \mathrm{eV}$, while the ratio of intensities of the satellite and of the main peak decreases from $0.15 \rightarrow 0.11 \rightarrow 0.07$. Apparently, bond covalency and electron delocalization within the lattice get successively stronger. While this is expected when passing from $\mathrm{F}^{-}$to the less electronegative oxygen ligand, structural differences are responsible for the additional change when proceeding to $\mathrm{NaCuO}_{2}$. This compound contains square planes of $\mathrm{CuO}_{4}[23,24]$, which are not isolated in the lattice as in $\mathrm{La}_{2} \mathrm{Li}_{1 / 2} \mathrm{Cu}_{1 / 2} \mathrm{O}_{4}$, but interconnected by common edges allowing for copper-copper interactions via oxygen bridges. As has been shown before [11,22], this structural situation favors electron delocaliza- 
tion, enhancing the copper-oxygen covalency as well as the transfer integral. The MOs of the copper polyhedra broaden by these cooperative metal-metal interactions leading to charge-transfer bands, which shift into the visible and even further to the IR spectral region [17]. In this way, black color, a narrow band gap, and chemical instability may originate, although the $(+$ III) oxidation state of copper seems to be still well defined. Thus, $\mathrm{NaCuO}_{2}$ is greyish black, in contrast to the brown and rather stable solid $\mathrm{La}_{2} \mathrm{Li}_{1 / 2} \mathrm{Cu}_{1 / 2} \mathrm{O}_{4}$.

In ceramic oxides with higher-valent $3 \mathrm{~d}$ metal ions, the first partly occupied or unoccupied state $\left(b_{1 g}^{*}\right.$ for $\mathrm{Cu}(\mathrm{III})$; see Fig. 1a) has a large weight of ligand $-2 p$ character due to covalent mixing, which is usually monitored by the ligand $-1 \mathrm{~s} \rightarrow 2 \mathrm{p}$ transition, i.e. preedge peaks in the $\mathrm{O}-\mathrm{K}$ and $\mathrm{F}-\mathrm{K}$ XANES spectra $[2,13,25]$. The gap decreases with increasing oxidation state of the metal ion. We therefore expect that the mentioned preedge peaks shift to lower energies in the sequence from $\mathrm{Cu}$ (II) to $\mathrm{Cu}$ (III) in oxide (fluoride) coordination.

Fig. 3 presents the $\mathrm{O}-\mathrm{K}$ and $\mathrm{F}-\mathrm{K}$ XANES spectra of $\mathrm{Cu}$ (III) compounds in comparison to those of the corresponding $\mathrm{Cu}$ (II) polyhedra in $\mathrm{CuO}$ and $\mathrm{CuF}_{2}$, respectively. The preedge peaks at $530.5 \mathrm{eV}$ for $\mathrm{CuO}$

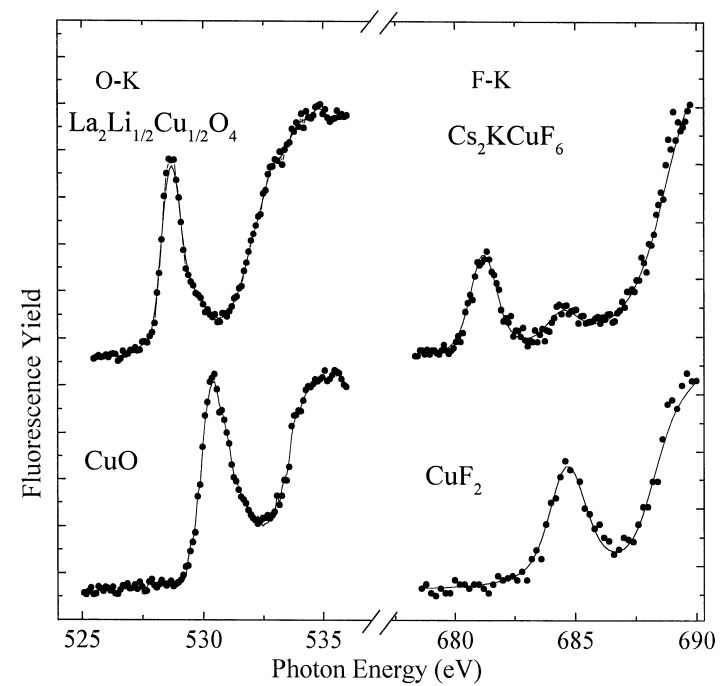

Fig. 3. O-K XANES spectra of $\mathrm{La}_{2} \mathrm{Li}_{1 / 2} \mathrm{Cu}_{1 / 2} \mathrm{O}_{4}$ and $\mathrm{CuO}$ (left panel), together with $\mathrm{F}-\mathrm{K}$ XANES spectra of $\mathrm{Cs}_{2} \mathrm{KCuF}_{6}$ and $\mathrm{CuF}_{2}$ (right panel). The solid curves through the data points of the two top spectra serve as a guide to the eyes. and $684.5 \mathrm{eV}$ for $\mathrm{CuF}_{2}$ are assigned to $1 \mathrm{~s} 3 \mathrm{~d}^{10}$ final states, with the intensities reflecting the hole fractions in the ligand $-2 \mathrm{p}$ states; the latter are proportional to $\beta_{0}^{2}$ (Eq. (3) with $n=9$ ) [13], since only intra-atomic XANES transition matrix elements are of finite magnitude. Shifts to lower energies of the first preedge peaks by $1.7 \mathrm{eV}$ for $\mathrm{La}_{2} \mathrm{Li}_{1 / 2} \mathrm{Cu}_{1 / 2} \mathrm{O}_{4}$ with respect to $\mathrm{CuO}$ and by $3.1 \mathrm{eV}$ for $\mathrm{Cs}_{2} \mathrm{KCuF}_{6}$ with respect to $\mathrm{CuF}_{2}$ were observed. If it is supposed that hole doping due to the replacement of $1 / 2 \mathrm{Cu}$ (II) by $1 / 2 \mathrm{Li}(\mathrm{I})$ occurs, in addition to the main peak, a further peak $1 \mathrm{~s} 3 \mathrm{~d}^{10}$ at about the same position as the preedge peak of $\mathrm{CuO}$ is expected. In fact, except for a small spectral weight due to a $\mathrm{CuO}$ impurity (see also Fig. 2), no such structure has been observed in the spectrum of Fig. 3. Thus according to Eq. (3) with $n=8$, the spectral weight of the first preedge peak for both copper solids, $\mathrm{Cs}_{2} \mathrm{KCuF}_{6}$ and $\mathrm{La}_{2} \mathrm{Li}_{1 / 2} \mathrm{Cu}_{1 / 2} \mathrm{O}_{4}$, seems to be proportional to $\beta_{0}^{2}$, indicating a (+III) oxidation state. This preedge peak had been observed previously for $\mathrm{La}_{2} \mathrm{Li}_{1 / 2} \mathrm{Cu}_{1 / 2} \mathrm{O}_{4}$, but it had been assigned to a doping hole, i.e. it served as an argument for a lacking $3 \mathrm{~d}^{8}$ participation in the ground state [8].

\section{2. $\mathrm{Ni}(\mathrm{II}) / \mathrm{Ni}(\mathrm{III})$}

In the following, we present our results for $\mathrm{Ni}(\mathrm{III})$ compounds and discuss them in comparison with $\mathrm{Cu}$ (III). $\mathrm{Nd}_{2} \mathrm{Li}_{1 / 2} \mathrm{Ni}_{1 / 2} \mathrm{O}_{4}$ crystallizes in the same ordered $\mathrm{K}_{2} \mathrm{NiF}_{4}$ structure as $\mathrm{La}_{2} \mathrm{Li}_{1 / 2} \mathrm{Cu}_{1 / 2} \mathrm{O}_{4}$ with isolated $\mathrm{Ni}(\mathrm{III}) \mathrm{O}_{6}$ polyhedra $[9,14]$. The $\mathrm{Ni}(\mathrm{III})$ centers have a low-spin electron configuration, which means that the single electron beyond the closed $\mathrm{d}^{6}$ configuration resides in an $\mathrm{a}_{1 \mathrm{~g}}^{*} \mathrm{MO}$; the electron configuration in the hole description is alg $\mathrm{b}^{* 2}$ (see Fig. 1a). The EPR spectra as well as ligand-field considerations give clear evidence for a less covalent $\mathrm{Ni}(\mathrm{III})-\mathrm{O}$ bond as compared to $\mathrm{Cu}(\mathrm{III})-\mathrm{O}$ in this type of solid [17].

The $\mathrm{Ni}-\mathrm{L}_{2,3}$ XANES spectra of $\mathrm{NiO}$ and $\mathrm{Nd}_{2} \mathrm{Li}_{1 / 2} \mathrm{Ni}_{1 / 2} \mathrm{O}_{4}$, displayed in Fig. 4, are more complex than those of the analogous copper systems (see Fig. 2); the reason is that the final states with more than one hole in the $3 \mathrm{~d}$-shell are subject to an extended multiplet structure due to interelectronic Coulomb interactions [26]. The spectral features for 
Ni(III) (see Fig. 4) exhibit obvious differences with respect to those of both the high-spin and the low-spin $\mathrm{Ni}(\mathrm{II})$ compounds studied so far [26,27], where at $\mathrm{L}_{3}$, the multiplet component $\mathrm{A}^{\prime}$ at lower energy always dominates; they are also different from a high-spin $\mathrm{Ni}^{3+}$ multiplet [27]. The well-resolved double-peaked XANES peaks at $\mathrm{L}_{3}$ and $\mathrm{L}_{2}$, with components $\mathrm{B}_{1}$ and $\mathrm{B}_{2}$ at $\mathrm{L}_{3}$, are shifted by 0.3 and $2.0 \mathrm{eV}$, respectively, to higher energies with respect to peak $\mathrm{A}^{\prime}$ in $\mathrm{NiO}$. This excludes a doping-hole origin, since the cluster model for $\mathrm{d}^{8} \mathrm{~L}$ yields only a broad and rather weak shoulder $\mathrm{B}_{2}$ [28]. Analogous to the case of $\mathrm{La}_{2} \mathrm{Li}_{1 / 2} \mathrm{Cu}_{1 / 2} \mathrm{O}_{4}$, there is also a broad, but somewhat weaker satellite $\mathrm{C}$ at $\cong 6 \mathrm{eV}$ above $\mathrm{B}_{2}$.

The ground state of $\mathrm{NiO}$, in the many-electron configuration-mixing model of Fig. 1b, is given by Eq. (3) with $n=8$. Similar to the $\mathrm{Cu}$ (II) case, $\alpha_{\mathrm{o}}$ is much larger than $\beta_{0}$, i.e. $\Delta \gg 0$ according to Eq.

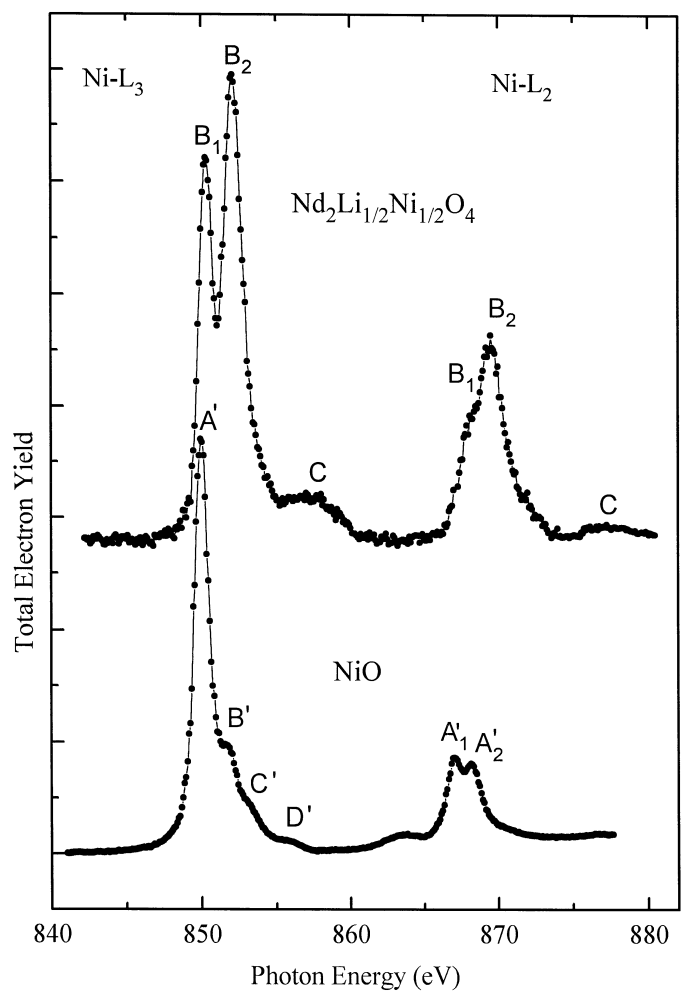

Fig. 4. Ni- $\mathrm{L}_{2,3}$ XANES spectra of $\mathrm{Nd}_{2} \mathrm{Li}_{1 / 2} \mathrm{Ni}_{1 / 2} \mathrm{O}_{4}$ and $\mathrm{NiO}$. The solid curves through the data points serve as a guide to the eyes.
(4). The main multiplet components $\mathrm{A}^{\prime}$ and $\mathrm{B}^{\prime}$ in the $\mathrm{L}_{3}$-XANES spectrum correspond to a $2 \mathrm{p}^{2} \mathrm{~d}^{9}$ final state and can be well reproduced by both an ionic ligand-field calculation [26] and the Anderson impurity model, with $\Delta=4.6 \mathrm{eV}$ and $T=1.5 \mathrm{eV}$ [19]; in the latter approach, the satellites $\mathrm{C}^{\prime}$ and $\mathrm{D}^{\prime}$ can also be described. When going from $\mathrm{NiO}$ to $\mathrm{Nd}_{2} \mathrm{Li}_{1 / 2} \mathrm{Ni}_{1 / 2} \mathrm{O}_{4}$, it is reasonable to assume that the decrease in the energy gap is comparable to the change between $\mathrm{CuO}$ and $\mathrm{La}_{2} \mathrm{Li}_{1 / 2} \mathrm{Cu}_{1 / 2} \mathrm{O}_{4}(\cong 2$ $\mathrm{eV})$. With the assumption that $\Delta$ decreases by $\cong 3$ $\mathrm{eV}$ when the charge on the $3 \mathrm{~d} \mathrm{Ni}$ cation increases by one unit charge [7], we arrive at $\Delta>0, \alpha_{0}>\beta_{0}$ for $\mathrm{Nd}_{2} \mathrm{Li}_{1 / 2} \mathrm{Ni}_{1 / 2} \mathrm{O}_{4}$, i.e. a ground state with a predominant $3 \mathrm{~d}^{7}$ contribution:

$\Phi_{\mathrm{g}}=\alpha_{0}\left|3 \mathrm{~d}^{7}\right\rangle+\beta_{0}\left|3 \mathrm{~d}^{8} \underline{\mathrm{L}}\right\rangle$.

In the alternative MO description, the ground-state electron configuration (in the hole notation) is alg big $_{12}^{2}$ (Fig. 1a). Mixing coefficients $\alpha^{\prime}=\sqrt{2 / 3}$ and $\bar{\beta}^{\prime}=\sqrt{1 / 3}$ (Eq. (1) with $\left.S=0\right)$ for both MOs $\left(\mathrm{a}_{1 \mathrm{~g}}^{*}\right.$, $\mathrm{b}_{1 \mathrm{~g}}^{*}$ ) reproduce $3 \mathrm{~d}^{8} \mathrm{~L}$, implying that in case of $\mathrm{Ni}(\mathrm{III})$ in oxidic coordination the bonding is much less covalent $\left(\alpha^{\prime}>\sqrt{2 / 3}, \quad \Delta^{\prime} \gg 0\right)$ than in case of $\mathrm{Cu}(\mathrm{III})\left(\alpha^{\prime}>\sqrt{1 / 2}, \Delta^{\prime}>0\right)$.

It may be useful to compare the energies of the main peaks in the spectra of $\mathrm{Nd}_{2} \mathrm{Li}_{1 / 2} \mathrm{Ni}_{1 / 2} \mathrm{O}_{4}$ and $\mathrm{NiO}$ - determined as the intensity-weighted averages over the multiplet splitting. The shift to higher energy by $\cong 1.4 \mathrm{eV}$ is comparable to the shift observed when passing from $\mathrm{Cu}$ (II) to $\mathrm{Cu}$ (III). Thole et al. have found that the branching ratio $I\left(\mathrm{~L}_{3}\right) /\left(I\left(\mathrm{~L}_{3}\right)+I\left(\mathrm{~L}_{2}\right)\right)$ depends on the occupancy and the spin-state of the $3 \mathrm{~d}$ shell. In case of $\mathrm{Ni}(\mathrm{II})$, the ratios are 0.732 and 0.692 for high-spin and low-spin, respectively [29], while they are 0.70 for high-spin and 0.63 for low-spin Ni(III). The ratio for $\mathrm{Nd}_{2} \mathrm{Li}_{1 / 2} \mathrm{Ni}_{1 / 2} \mathrm{O}_{4}$ is 0.65 , which is in agreement with the EPR evidence of a low-spin configuration [9]. A striking difference between $\mathrm{Nd}_{2} \mathrm{Li}_{1 / 2} \mathrm{Ni}_{1 / 2} \mathrm{O}_{4}$ and $\mathrm{NiO}$ is also seen at the $\mathrm{Ni}-\mathrm{L}_{2}$ threshold. While for cubic $\mathrm{NiO}$, two peaks $\mathrm{A}_{1}^{\prime}$ and $\mathrm{A}_{2}^{\prime}$ of about equal intensity are observed at $\mathrm{L}_{2}$, the higher-energy peak $\mathrm{B}_{2}$ is again dominant in the spectrum of $\mathrm{Nd}_{2} \mathrm{Li}_{1 / 2} \mathrm{Ni}_{1 / 2} \mathrm{O}_{4}$, and the center of the spectral weight is shifted by $\cong 1.3 \mathrm{eV}$ to higher energy. 
Crystal-field multiplet calculations for $\mathrm{L}_{2}$ XANES of $\mathrm{Ni}(\mathrm{II})$ in $\mathrm{D}_{4 \mathrm{~h}}$ symmetry yield a double-peaked structure for a high-spin and a single peak for a low-spin configuration [27]. It is known that configuration-mixing results in a strong change of the multiplet structure of the main peak in the $\mathrm{M}_{4,5}$ XANES spectra of tetravalent rare-earth cations, e.g. in compounds like $\mathrm{PrO}_{2}$ [21]. To understand the spectral features observed for $\mathrm{Nd}_{2} \mathrm{Li}_{1 / 2} \mathrm{Ni}_{1 / 2} \mathrm{O}_{4}$ in more detail, both atomic multiplet effects and interatomic covalent interactions have to be included in the calculations (see Section 4). We conclude that the $\mathrm{Ni}(\mathrm{III})-\mathrm{O}$ bond possesses distinct covalent contributions, though the degree of covalency is much weaker than in case of the $\mathrm{Cu}$ (III)-O bond, in agreement with chemical experience. Further support for this argument comes from the O-K XANES spectra.

Fig. 5 shows the $\mathrm{O}-\mathrm{K}$ XANES spectra of $\mathrm{Nd}_{2} \mathrm{Li}_{1 / 2} \mathrm{Ni}_{1 / 2} \mathrm{O}_{4}$ and $\mathrm{NiO}$. In the spectrum of $\mathrm{NiO}$, the intensity of the preedge peak at about $532 \mathrm{eV}$ monitors the $\mathrm{O}-2 \mathrm{p}$ hole concentration in a predominantly $\mathrm{Ni}-3 \mathrm{~d}^{8}$ state, similar to the case of $\mathrm{CuO}$; it was assigned to a $1 \mathrm{~s} 3 \mathrm{~d}^{9}$ final state [13]. In $\mathrm{Nd}_{2} \mathrm{Li}_{1 / 2} \mathrm{Ni}_{1 / 2} \mathrm{O}_{4}$, the narrow preedge peak assigned to basically $1 \mathrm{~s} 3 \mathrm{~d}^{9}$ is shifted by $2.6 \mathrm{eV}$ to lower energy as compared to $\mathrm{NiO}$. The preedge peak in the XANES spectrum of $\mathrm{CuO}$ is shifted by $1.5 \mathrm{eV}$

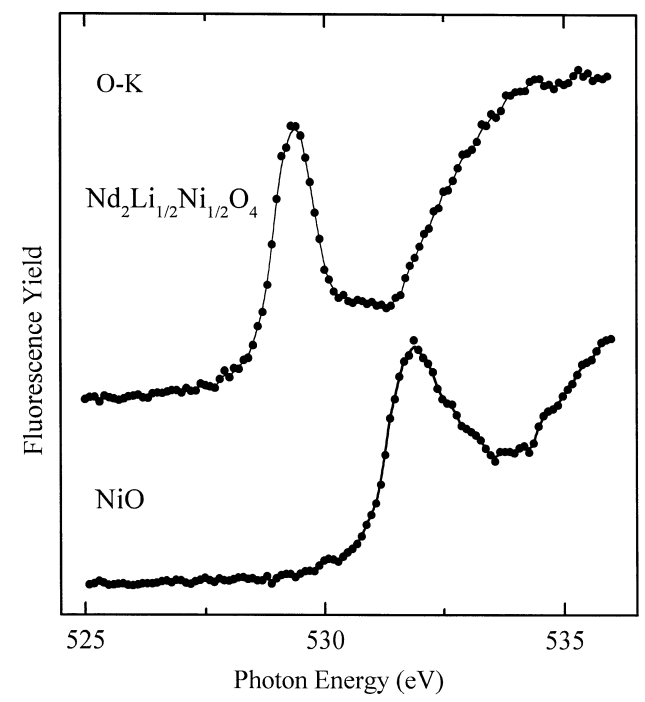

Fig. 5. O-K XANES spectra of $\mathrm{Nd}_{2} \mathrm{Li}_{1 / 2} \mathrm{Ni}_{1 / 2} \mathrm{O}_{4}$ and $\mathrm{NiO}$. The solid curves through the data points serve as a guide to the eyes. to lower energy relative to the one of NiO. Similarly, there is a shift of $0.8 \mathrm{eV}$ to lower energy when passing from $\mathrm{Nd}_{2} \mathrm{Li}_{1 / 2} \mathrm{Ni}_{1 / 2} \mathrm{O}_{4}$ to $\mathrm{La}_{2} \mathrm{Li}_{1 / 2} \mathrm{Cu}_{1 / 2} \mathrm{O}_{4}$, which indicates a shrinkage of the energy gap when going from $\mathrm{Ni}(\mathrm{II})[\mathrm{Ni}(\mathrm{III})]$ to $\mathrm{Cu}(\mathrm{II})[\mathrm{Cu}(\mathrm{III})]$. This point has been discussed explicitly above. Sugiura et al. have found a systematic shift of the preedge peak to lower energy when the ionization energy of the metal ion in the same oxidation state increases [30,31]. Indeed, the second ionization energy increases from $18.17 \mathrm{eV}$ for $\mathrm{Ni}(\mathrm{II})$ to $20.29 \mathrm{eV}$ for $\mathrm{Cu}$ (II), while the third ionization energy is $35.17 \mathrm{eV}$ for $\mathrm{Ni}(\mathrm{III})$ and $36.84 \mathrm{eV}$ for $\mathrm{Cu}(\mathrm{III})$ [32]. This consideration predicts a decrease of the gap from $\mathrm{Ni}(\mathrm{II})$ [ $\mathrm{Ni}(\mathrm{III})$ ] to $\mathrm{Cu}$ (II) [Cu(III)], as is indeed observed, and hence an increase in covalency when going from $\mathrm{Ni}(\mathrm{II})$ to $\mathrm{Ni}(\mathrm{III})$ or from $\mathrm{Ni}$ (III) to $\mathrm{Cu}(\mathrm{III})$. On the basis of these arguments, we can also understand the more pronounced metallic properties of $\mathrm{La}_{2-x} \mathrm{Sr}_{x} \mathrm{MO}_{4}$ materials for $\mathrm{M}=\mathrm{Cu}$ as compared to $\mathrm{M}=\mathrm{Ni}$.

Since the preedge peak in the O-K XANES spectrum of $\mathrm{NiO}$ lies almost at the same energy as the $5 \mathrm{~d}$ state of $\mathrm{Nd}(\mathrm{III})$ in $\mathrm{Nd}_{2} \mathrm{Li}_{1 / 2} \mathrm{Ni}_{1 / 2} \mathrm{O}_{4}$, we can not exclude that a few per cent $\mathrm{Ni}$ (II) impurities are partly responsible for the weak broad shoulder at $\cong 532 \mathrm{eV}$ in the $\mathrm{O}-\mathrm{K}$ XANES spectrum of $\mathrm{Nd}_{2} \mathrm{Li}_{1 / 2} \mathrm{Ni}_{1 / 2} \mathrm{O}_{4}$. At this point, it is interesting to compare $\mathrm{Nd}_{2} \mathrm{Li}_{1 / 2} \mathrm{Ni}_{1 / 2} \mathrm{O}_{4}$ with $\mathrm{Li}_{x} \mathrm{Ni}_{1-x} \mathrm{O}$. In the latter mixed crystals one has widely interconnected $\mathrm{NiO}_{6}$ octahedra and - in addition - Ni(II) and $\mathrm{Ni}$ (III) centers side by side. This situation suggests an extended charge-transfer between the nickel centers in the lattice. As has been shown elsewhere $[11,17]$, these structural and valence properties induce a very distinct shift of the charge-transfer bands into the visible region. The corresponding decrease of the gap is indeed reflected in a shift to lower energy of the preedge peak by $0.8 \mathrm{eV}$ when going from $\mathrm{Nd}_{2} \mathrm{Li}_{1 / 2} \mathrm{Ni}_{1 / 2} \mathrm{O}_{4}$ to $\mathrm{Li}_{x} \mathrm{Ni}_{1-x} \mathrm{O}$, as well as in an increase of the intensity of the preedge peak for $x>0.3[13,29]$. Note that in case of $\mathrm{Li}_{x} \mathrm{NiO}_{1-x}$, the structure at the energy of the preedge peak in the XANES spectrum of $\mathrm{NiO}$ is not present, suggesting that the shoulder at this energy in the XANES spectrum of $\mathrm{Nd}_{2} \mathrm{Li}_{1 / 2} \mathrm{Ni}_{1 / 2} \mathrm{O}_{4}$ originates partly from $\mathrm{Nd}(\mathrm{III})-5 \mathrm{~d}$. From the standpoint of hole doping, one could be misled by assuming comparable $3 \mathrm{~d}^{8} \underline{\mathrm{L}}$ con- 
tributions to the ground states of both $\mathrm{Nd}_{2} \mathrm{Li}_{1 / 2} \mathrm{Ni}_{1 / 2} \mathrm{O}_{4}$ and $\mathrm{Li}_{1 / 2} \mathrm{Ni}_{1 / 2} \mathrm{O}$. The different intensity distributions in the $\mathrm{Ni}-\mathrm{L}_{2,3}$ XANES spectra of the two solids and the considerably larger line widths in case of $\mathrm{Li}_{x} \mathrm{NiO}_{1-x}$ [29], however, reveal, that this is not real. As a matter of fact, a more pronounced ionic $3 \mathrm{~d}^{7}$ contribution has to be considered in case of $\mathrm{Nd}_{2} \mathrm{Li}_{1 / 2} \mathrm{Ni}_{1 / 2} \mathrm{O}_{4}$. We would further like to point out that for $\mathrm{LiNiO}_{2}\left(\mathrm{NaCuO}_{2}\right)$ also $3 \mathrm{~d}^{9} \mathrm{~L}^{2}$ $\left(3 \mathrm{~d}^{10} \mathrm{~L}^{2}\right)$ contributions to the ground state have to $\overline{b e}$ considered, if not only charge transfer within the $\mathrm{M}(\mathrm{III})-\mathrm{O}_{6}$ cluster is taken into account, but also non-local effects with electron delocalization to more remote ligands.

\section{Results of calculations}

We have performed charge-transfer multipletcalculations using our TT-MULTIPLETS program in order to make a detailed comparison with the spectral shapes. This program consists of a package of programs including parts of the atomic multiplet program of Cowan [32], the group-theory program of Butler [33], and the charge-transfer program of Okada et al. [34]. The calculational method follows the procedure outlined in Section 3. The ground state of $\mathrm{Cu}(\mathrm{III})$ is described by a linear combination of $3 \mathrm{~d}^{8}$ and $3 \mathrm{~d}^{9} \mathrm{~L}$ states. In Section 3, this has been described by a $2 \times 2$ matrix, but in the actual calculations, the dimensions of the various multiplet states must be used, being 45 for $3 d^{8}$ and 60 for $3 d^{9} L$ (reduced by symmetry). The matrix consists of $45 \overline{\times} 45$ and $60 \times$ 60 diagonal blocks mixed together by hopping. Depending on the assumed symmetry, the actual matrices are smaller. Because of this the determination of the mixing coefficients, as given by Eq. (4), is only approximate.

The bottom part of Fig. 6 shows a comparison between theory and experiment for $\mathrm{Cs}_{2} \mathrm{KCuF}_{6}$. The vertical bars represent the energies and intensities obtained in the calculations and the solid curve represents the spectrum obtained by inclusion of a life-time broadening of $0.6 \mathrm{eV}$ at the $\mathrm{L}_{3}$ threshold $\left(0.90 \mathrm{eV}\right.$ at $\left.\mathrm{L}_{2}\right)$, plus an experimental broadening of $0.6 \mathrm{eV}$ (FWHM, Gaussian). All structures observed in the experiment are well reproduced in the calculation, with the exception of the $\mathrm{L}_{3}$ peak at $\cong 930 \mathrm{eV}$

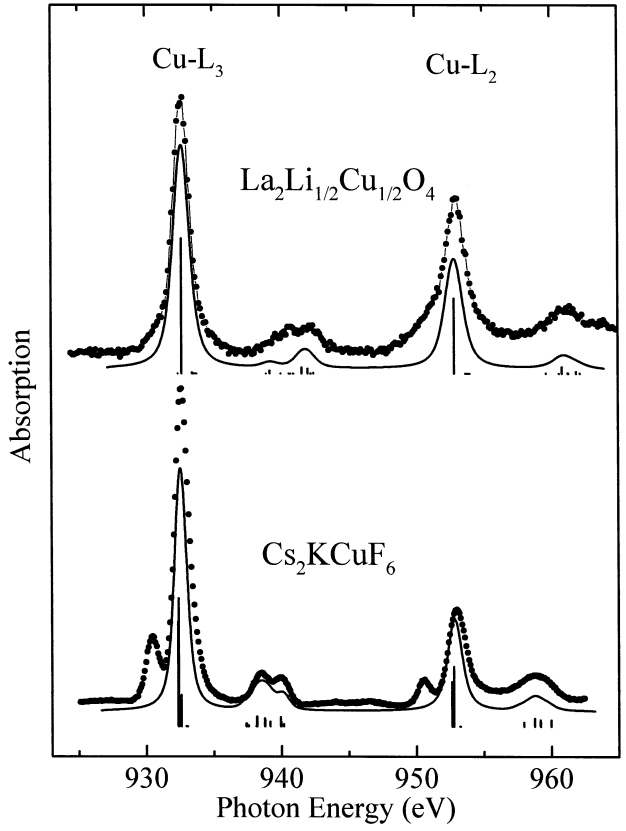

Fig. 6. Results of theoretical simulations (vertical bars and solid curves) of the $\mathrm{Cu}-\mathrm{L}_{2,3}$ XANES spectra of $\mathrm{Cs}_{2} \mathrm{KCuF}_{6}$ (bottom) and $\mathrm{La}_{2} \mathrm{Li}_{1 / 2} \mathrm{Cu}_{1 / 2} \mathrm{O}_{4}$ (top), in comparison with the experimental spectra (filled circles).

and the $\mathrm{L}_{2}$ peak at $\cong 950 \mathrm{eV}$, both originating from $\mathrm{Cu}$ (II) impurities due to sample degradation. The sharp main peak and the double-peaked structure at $\cong 940 \mathrm{eV}$ are both nicely reproduced. The main peak is dominated by $2 \mathrm{p} 3 \mathrm{~d}^{10} \mathrm{~L}$ character, and the double peak relates to the $2 \overline{\mathrm{p}} 3 \mathrm{~d}^{9}$-dominated final state, displaying a multiplet structure, which is formed by a combination of multiplet $(2 \mathrm{p} 3 \mathrm{~d}$ interaction), crystal-field, and charge-transfer effects. Position and intensity of this structure with respect to the main peak determine essentially the amount of mixing and the separation of the peaks; this sets limits to the values of $\Delta$ as well as to hopping. The comparison shows that the spectrum of $\mathrm{Cs}_{2} \mathrm{KCuF}_{6}$ can be simulated by using $\Delta=-1.3 \mathrm{eV}$. Following the literature [35,36], $\Delta$ is defined as the energy difference between the lowest $3 d^{8}$ and the lowest $3 d^{9} L$ state. The multiplet calculations require as an input parameter the energy difference $\Delta$ (average) between the centers-of-gravity of $3 \mathrm{~d}^{8}$ and $3 \mathrm{~d}^{9} \mathrm{~L}$, which is equal to $-3.0 \mathrm{eV}$. Multiplet and crystal-field effects stabilize the $3 \mathrm{~d}^{8}$ configuration by $-1.7 \mathrm{eV}$, yielding 
a $\Delta$ value of $-1.3 \mathrm{eV}$. The mixing parameters are $2.0 \mathrm{eV}$ for $\mathrm{E}_{\mathrm{g}}$ mixing and $1.0 \mathrm{eV}$ for $\mathrm{T}_{2 \mathrm{~g}}$ mixing (using the rule that for octahedral symmetry, $E_{g}$ mixing is twice as strong as $\mathrm{T}_{2 \mathrm{~g}}$ mixing) [37,38]. Atomic Slater integrals have been used in all simulations [26], with an ionic crystal-field value (10 Dq) of $0.5 \mathrm{eV}$. These parameters define the ground state as a ${ }^{3} \mathrm{~A}_{2}$ state with approximately $40 \% 3 \mathrm{~d}^{8}$ character. The final state is a linear combination of the multiplets $2 \mathrm{p} 3 \mathrm{~d}^{9}$ and $2 \mathrm{p} 3 \mathrm{~d}^{10} \mathrm{~L}$. As discussed in Section 3 , the energy difference is equal to $\Delta$ (average) $-2.0 \mathrm{eV}$, which amounts to $-1.0 \mathrm{eV}$.

The spectrum of $\mathrm{La}_{2} \mathrm{Li}_{1 / 2} \mathrm{Cu}_{1 / 2} \mathrm{O}_{4}$ can be simulated in a similar way. Using again $\Delta($ average $)=$ $-3.0 \mathrm{eV}, \Delta$ is obtained as $-1.9 \mathrm{eV}$. The $\mathrm{D}_{4 \mathrm{~h}}$ symmetry of the strongly elongated $\mathrm{CuO}_{6}$ polyhedron in $\mathrm{La}_{2} \mathrm{Li}_{1 / 2} \mathrm{Cu}_{1 / 2} \mathrm{O}_{4}$ is described by an (ionic) octahedral crystal field of $0.5 \mathrm{eV}$, with $\mathrm{Ds}=0.3 \mathrm{eV}$. Additionally, the mixing terms are separated into four symmetries, $A_{1 g}, B_{1 g}, A_{2 g}$, and $E_{g}$, using the relations between these as described by Eskes et al. [39]. The respective mixing terms are 3.0, 1.73, 1.5, and $1.03 \mathrm{eV}$. The resulting many-electron ground state is ${ }^{1} \mathrm{~A}_{1 \mathrm{~g}}$, with both holes in the $x^{2}-y^{2}$ orbital. The percentage of $3 \mathrm{~d}^{8}$ character is found to be $30 \%$. It can be deduced from Fig. 6 (top) that the theoretical multiplet structure of the $2 \mathrm{p}^{2} \mathrm{~d}^{9}$ state contains two peaks separated by $\cong 3 \overline{\mathrm{eV}}$, which have not been resolved in the experiments. The very weak spectral intensities at $\cong 930$ and $950 \mathrm{eV}$ are again caused by $\mathrm{Cu}$ (II) impurities.

Fig. 7 gives a comparison between theory and experiment for $\mathrm{Nd}_{2} \mathrm{Li}_{1 / 2} \mathrm{Ni}_{1 / 2} \mathrm{O}_{4}$. At the $\mathrm{L}_{3}$ threshold, a double-peaked structure is observed, which is quite unique for $\mathrm{Ni}$ compounds with a satellite structure at higher energies. The theoretical spectrum has been calculated using a $\Delta$ value of $+0.5 \mathrm{eV}$ (related to a $\Delta$ (average) value of $-1.0 \mathrm{eV}$ ). The mixing parameters are equal to those of $\mathrm{La}_{2} \mathrm{Li}_{1 / 2} \mathrm{Cu}_{1 / 2} \mathrm{O}_{4}$, because the $\mathrm{MO}_{6}$ polyhedra $(\mathrm{M}=\mathrm{Cu}, \mathrm{Ni})$ have a similar geometry [14]. Also, the ionic crystal-field values have been set equal $(10 \mathrm{Dq}=0.5 \mathrm{eV}$; $\mathrm{Ds}=0.3$ $\mathrm{eV})$. These values determine the $\mathrm{Ni}(\mathrm{III})$ ground state as low-spin, ${ }^{2} \mathrm{~A}_{1 \mathrm{~g}}$, approximately related to two holes in the $x^{2}-y^{2}$ orbital, with the third hole in the $z^{2}$ state (Fig. 1a). Because $\Delta$ is close to zero, the ground state contains almost equal amounts of $3 \mathrm{~d}^{7}$ and $3 d^{8} \underline{L}$; the actual percentage of $3 d^{7}$ is $57 \%$. This

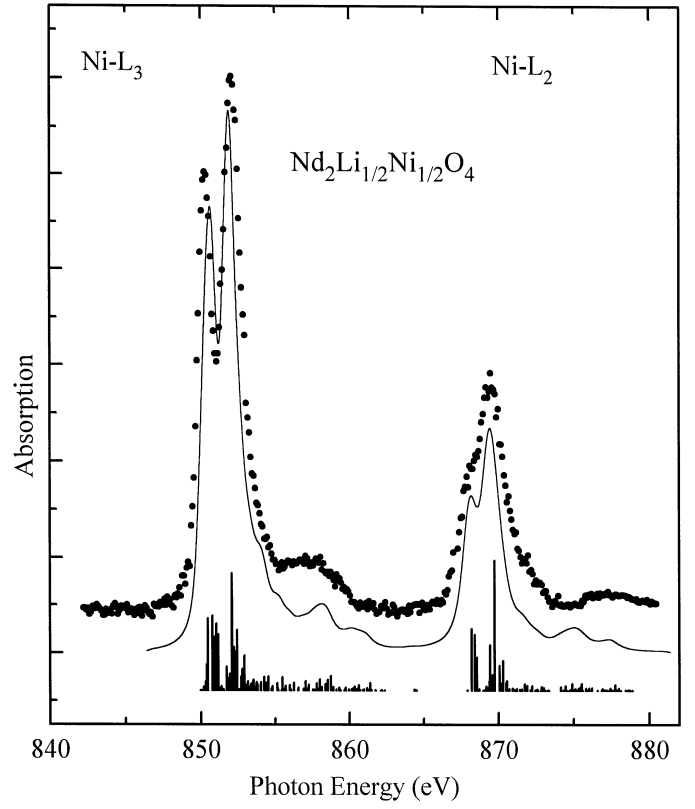

Fig. 7. Result of theoretical simulation (vertical bars and solid curve) of the $\mathrm{Ni}-\mathrm{L}_{2,3}$ XANES spectrum of $\mathrm{Nd}_{2} \mathrm{Li}_{1 / 2} \mathrm{Ni}_{1 / 2} \mathrm{O}_{4}$, in comparison with the experimental spectrum (filled circles).

strongly intermixed ground state makes it doubtful to assign a particular final-state configuration to a particular peak. It is best to say that the whole spectral shape is given by strongly mixed $2 \mathrm{p}^{3} \mathrm{~d}^{8}$ and $2 \mathrm{p} 3 \mathrm{~d}^{9} \mathrm{~L}$ states. The theoretical simulation clearly proves the ${ }^{2} \mathrm{~A}_{1 \mathrm{~g}}$ low-spin nature of $\mathrm{Ni}(\mathrm{III})$ in $\mathrm{Nd}_{2} \mathrm{Li}_{1 / 2} \mathrm{Ni}_{1 / 2} \mathrm{O}_{4}$, in agreement with the spectral shape as well as the EPR results with $60 \% 3 \mathrm{~d}^{7}$ and $40 \% 3 \mathrm{~d}^{8} \mathrm{~L}$ character [14].

\section{Conclusions}

In order to shed light on the bonding properties of $\mathrm{Cu}$ (III) and $\mathrm{Ni}$ (III) in fluoridic and oxidic solid compounds, we have studied the XANES spectra at the $\mathrm{Cu}-\mathrm{L}_{2,3}, \mathrm{Ni}-\mathrm{L}_{2,3}, \mathrm{O}-\mathrm{K}$, and $\mathrm{F}-\mathrm{K}$ thresholds of $\mathrm{La}_{2} \mathrm{Li}_{1 / 2} \mathrm{Cu}_{1 / 2} \mathrm{O}_{4}, \quad \mathrm{Cs}_{2} \mathrm{KCuF}_{6}$, and $\mathrm{Nd}_{2} \mathrm{Li}_{1 / 2} \mathrm{Ni}_{1 / 2} \mathrm{O}_{4}$, in which non-local effects such as charge transfer to neighboring clusters can be excluded due to the proper choice of the host structures [14]. The observed main peaks and satellites in the $\mathrm{Cu}(\mathrm{III})-$ and $\mathrm{Ni}(\mathrm{III})-\mathrm{L}_{2,3}$ XANES spectra are basically assigned to bonding and antibonding com- 
binations of $2 p 3 d^{9}$ and $2 p 3 d^{10} L$ configurations for $\mathrm{Cu}(\mathrm{III})$ and the corresponding combinations of $2 \mathrm{p} 3 \mathrm{~d}^{8}$ and $2 \mathrm{p} 3 \mathrm{~d}^{9} \mathrm{~L}$ for $\mathrm{Ni}(\mathrm{III})$. The larger spectral weights of the satellites in the XANES spectra of the investigated compounds as compared to the previously studied compounds $\mathrm{NaCuO}_{2}$ and $\mathrm{Li}_{x} \mathrm{Ni}_{1-x} \mathrm{O}$ indicate lower bond covalencies. The larger ionic contribution in case of $\mathrm{Nd}_{2} \mathrm{Li}_{1 / 2} \mathrm{Ni}_{1 / 2} \mathrm{O}_{4}$ is further reflected in the well-resolved doublet structure of the main peak. Non-local charge transfer to neighboring clusters, as present, e.g. in the interconnected $\mathrm{MO}_{6(4)}$ polyhedra $[\mathrm{M}=\mathrm{Ni}(\mathrm{III}), \mathrm{Cu}(\mathrm{III})]$ of $\mathrm{LiNiO}_{2}$ and $\mathrm{NaCuO}_{2}$, would lead to a smaller charge-transfer energy, $\Delta$, and hence to an enhancement of the metal-3d/ligand-2p mixing, as known from corelevel XPS studies [11,22]. The decrease of $\Delta$ with increasing oxidation state and atomic number of the $3 \mathrm{~d}$ transition-metal atom is also indicated by the lower energy shifts of the preedge peaks in the XANES spectra at the $\mathrm{O}-\mathrm{K}$ and $\mathrm{F}-\mathrm{K}$ thresholds $(\mathrm{Ni}(\mathrm{II}) \rightarrow \mathrm{Ni}(\mathrm{III}) \rightarrow \mathrm{Cu}(\mathrm{III})$ ).

The results obtained within the framework of the one-electron MO description, widely used by chemists, can be supplemented by the following comments, referring to Fig. 1a and Eq. (1): For isolated $\mathrm{MO}_{6(4)}$ polyhedra, the mixing coefficient $\alpha^{\prime}$ is larger than $\beta^{\prime}$, and the energy separation $\Delta^{\prime}>0$, with $\alpha^{\prime}$ and $\Delta^{\prime}$ increasing from $\mathrm{M}=\mathrm{Cu}(\mathrm{III}) \rightarrow$ $\mathrm{Ni}(\mathrm{III})$, in accordance with chemical experience. The dominant $3 \mathrm{~d}^{9} \mathrm{~L}$ contribution to the ground state of $\mathrm{Cu}(\mathrm{III})$ in oxidic coordination should not be interpreted as ' $\mathrm{Cu}^{2+}-\mathrm{O}^{-}$, , but corresponds to the $\mathrm{MO}$ configuration $\mathrm{b}_{1 \mathrm{~g}}^{* 2}$, with the two holes equally distributed between $\mathrm{Cu}(\mathrm{III})$ and oxygen.

Detailed configuration-interaction multiplet calculations for the $\mathrm{Cu}$ (III) systems have shown that the multiplet structures allow a distinction between high-spin and low-spin $3 \mathrm{~d}^{8}$-like $\mathrm{Cu}$ (III) sites. Both are dominated by $3 \mathrm{~d}^{9} \mathrm{~L}$ character, the high-spin (fluoride) compound with $\cong 40 \% 3 \mathrm{~d}^{8}$ and the low-spin (oxide) compound with $\cong 30 \% 3 \mathrm{~d}^{8}$. These fractions are determined by the interplay between $\Delta$ and the hopping terms. The more negative $\Delta$ value of the low-spin compound induces a more pronounced $3 \mathrm{~d}^{9} \mathrm{~L}$ character. In case of $\mathrm{Nd}_{1 / 2} \mathrm{Li}_{1 / 2} \mathrm{Ni}_{1 / 2} \mathrm{O}_{4}$, the multiplet calculations clearly show that the $\mathrm{Ni}$ (III) ground state is low spin, with a rather strong $60 \%$ contribution of $3 d^{7}$ and a $40 \%$ admixture of $3 d^{8} \mathrm{~L}$.

\section{Acknowledgements}

The work of the Berlin group was supported by the Bundesminister für Bildung, Wissenschaft, Forschung und Technologie, Project 05 650KEA, and the Deutsche Forschungsgemeinschaft, Project Ka 564/7-1. The research of FdG has been made possible by the Royal Netherlands Academy of Arts and Sciences (KNAW).

\section{References}

[1] M. Khairy, P. Odier, J. Choisnet, J. Phys. Collog. C 147 (1986) 831.

[2] P. Kuiper, J. van Elp, G.A. Sawatzky, A. Fujimori, S. Hosoya, D.M. de Leeuw, Phys. Rev. B 44 (1991) 4570.

[3] H. Eisaki, S. Uchida, T. Mizokawa, H. Namatame, A. Fujimori, J. van Elp, P. Kuiper, G.A. Sawatzky, S. Hosoya, H. Katayama-Yoshida, Phys. Rev. B 44 (1992) 4570.

[4] E. Pellegrin, C.T. Chen, J. Zaanan, J. Fink, Physica B 208 (1995) 487

[5] G. Kaindl, O. Strebel, O. Kolodziejczky, A. Schäfers, W. Kiems, R. Lösch, S. Kemmler-Sack, R. Hoppe, H.P. Müller, D. Kissel, Physica B 158 (1989) 446.

[6] T. Mizokawa, H. Namatame, K. Fujimori, H. Akeyama, H. Kondoh, H. Kurada, N. Kosugi, Phys. Rev. Lett. 67 (1991) 1638.

[7] T. Mizokawa, A. Fujimori, H. Namatame, K. Akeyama, N. Kosugi, Phys. Rev. B 49 (1994) 7193.

[8] N. Merrien, F. Studer, C. Michel, P. Srivastava, B.R. Sekhar, N.L. Saini, K.B. Garg, G. Tourillon, J. Phys. Chem. Solids 54 (1993) 499.

[9] D. Reinen, U. Kesper, D. Belder, J. Solid State Chem. 116 (1995) 3555.

[10] K. Okada, A. Kotani, B.T. Thole, G.A. Sawatzky, Solid State Commun. 77 (1991) 835

[11] M. Atanasov, D. Reinen, J. Electron. Spectrosc. Rel. Phen. 86 (1997) 180, (celebration volume B.T. Thole).

[12] M.A. Van Veenendaal, H. Eskes, G.A. Sawatzky, Phys. Rev. B 47 (1993) 11462.

[13] P. Kuiper, G. Kruizinga, J. Ghijsen, G.A. Sawatzky, H. Verweij, Phys. Rev. Lett. 62 (1989) 221.

[14] S.A. Warda, W. Pietzuch, U. Kesper, W. Massa, D. Reinen, J. Solid State Chem. (1998) in press, and references therein.

[15] R. Hoppe, R. Homann, Naturwissenschaften 53 (1966) 501.

[16] G.C. Allen, K.D. Warren, Struct. Bond. 9 (1971) 49.

[17] D. Reinen, J. Wegwerth, Physica C 183 (1991) 261.

[18] Z. Hu, G. Kaindl, B.G. Müller, J. Alloys Compounds 246 (1997) 177.

[19] G. Van der Laan, B.T. Thole, G.A. Sawatzky, R. Karnatak, J.-M. Esteva, Phys. Rev. B 33 (1986) 4235.

[20] O. Strebel, Doctoral Thesis, Freie Universität Berlin, 1994.

[21] H. Ogasawara, A. Kotani, K. Okada, B.T. Thole, Phys. Rev. B 43 (1991) 854. 
[22] K. Okada, A. Kotani, J. Electron. Spectrosc. Rel. Phen. 86 (1997) 208, (celebration volume B.T. Thole).

[23] K. Hestermann, R. Hoppe, Z. Anorg. Allg. Chem. 367 (1969) 249.

[24] K. Hestermann, R. Hoppe, Z. Anorg. Allg. Chem. 367 (1969) 261.

[25] F.M.F. De Groot, M. Grioni, J.C. Fuggle, J. Ghijsen, G.A. Sawatzky, Phys. Rev. B 41 (1989) 5715.

[26] F.M.F. De Groot, J.C. Fuggle, B.T. Thole, G.A. Sawatzky, Phys. Rev. B 42 (1990) 5459.

[27] G. Van der Laan, B.T. Thole, G.A. Sawatzky, M. Verdaguer, Phys. Rev. B 37 (6587) (1988) .

[28] P. Kuiper, Doctoral Thesis, Rijksuniversiteit Groningen, The Netherlands, 1990.

[29] B.T. Thole, G. van der Laan, Phys. Rev. B 38 (1988) 3158.
[30] C. Sugiura, J. Chem. Phys. 58 (1972) 5444.

[31] C. Sugiura, T.J. Suzuki, J. Chem. Phys. 75 (1981) 4357.

[32] T. Cowan, The Theory of Atomic Structure and Spectra (University of California Press, Berkeley, CA, 1981).

[33] P.H. Butler, Point Group Symmetry, Applications, Methods and Tables (Plenum Press, New York, 1981).

[34] K. Okada, A. Kotani, B.T. Thole, J. Electron. Spectrosc. Rel. Phen. 58 (1992) 325.

[35] J. Zaanen, G.A. Sawatzky, J.W. Allen, Phys. Rev. Lett. 55 (1985) 418.

[36] A. Fujimori, F. Minami, Phys. Rev. B 30 (1984) 957.

[37] L.F. Mattheiss, Phys. Rev. B 5 (1972) 290.

[38] L.F. Mattheiss, Phys. Rev. B 5 (1972) 306.

[39] H. Eskes, G.A. Sawatzky, Phys. Rev. B 43 (1991) 119. 